\title{
Participação, desenvolvimento local e política pública: estratégias articuladas para a superação da pobreza
}

\author{
Antonio David Cattani \\ Universidade Federal do Rio Grande do Sul (Ufrgs)
}

\author{
Adriane Vieira Ferrarini \\ Universidade do Vale do Rio dos Sinos (Unisinos)
}

Participação, desenvolvimento local e política pública: estratégias articuladas para a superação da pobreza

Resumo: Este artigo analisa a possibilidade de uma política pública na área do planejamento urbano promover a superação da pobreza na medida em que incorpore estratégias ligadas ao desenvolvimento local e às metodologias participativas. A pesquisa empírica foi realizada no Programa Integrado de Recuperação de Áreas Degradadas (Pirad), desenvolvido pela Fundação Estadual de Planejamento Metropolitano e Regional (Metroplan) no estado do Rio Grande do Sul, através de análise documental, observação participante, entrevistas semiestruturadas com técnicos e beneficiários, e estudo de caso numa das comunidades envolvidas. A articulação entre política pública, desenvolvimento local e metodologias participativas gerou impactos voltados para a superação emancipatória e sustentável da pobreza através do fortalecimento da participação da população como cogestora do Programa, da ativação de recursos locais e da articulação de ações setoriais no território.

Palavras-chave: participação, desenvolvimento local, políticas públicas, pobreza.

\section{Participation, Local Development and Public Policy: Strategies Articulated to Overcome Poverty}

Abstract: This article analyzes the possibility for public policy in the field of urban planning to help overcome poverty to the degree to which the policy incorporates strategies linked to local development and participative methodologies. The empiric study was conducted in the Integrated Program for the Recovery of Degraded Areas (PIRAD), undertaken by the State Foundation for Metropolitan and Regional Planning (Metroplan) in Rio Grande do Sul State. It involved document analysis, participant observation, semi-structured interviews with technicians and beneficiaries, and a case study in one of the communities involved. The articulation between public policy, local development and participative methodologies generated results that contribute to a sustainable and liberating overcoming of poverty by strengthening the participation of the population as co-administrators of the program, of the activation of local resources and of articulation of sectorial actions in the territory.

Key words: participation, local development, public policies, poverty. 


\section{Introdução}

O tema pobreza e suas formas de superação têm sido foco de muitos estudos, pesquisas e debates nas últimas décadas no Brasil e no mundo. Ao longo da história, à pobreza têm sido atribuídos diferentes conceitos que correspondem a determinadas formas de intervenção social. Durante séculos predominaram concepções individualizantes e patologizantes acerca da pobreza, vista como problema ligado ao caráter e a idiossincrasias dos sujeitos. Posteriormente, a teoria crítica marxiana possibilitou o desvendamento do caráter estrutural da pobreza, salientando sua gênese econômica ligada à forma como os sujeitos estão inseridos na esfera produtiva, tendo posse ou não dos meios de produção.

Tanto em perspectivas teóricas críticas quanto conservadoras ou liberais, a pobreza tem sido historicamente conceituada como insuficiência de renda e carência de recursos materiais necessários à vida. Em termos metodológicos, Comim e Bagolin (2002) referem que os pesquisadores tendem a fixar-se em aspectos materiais pela razão óbvia de que dados empíricos e quantificáveis de renda são mais fáceis de lidar. Outra razão está relacionada à própria natureza do capitalismo; pela primeira vez na história, a dimensão econômica mostra-se central para a caracterização e a dinâmica das formações sociais.

Nos últimos 20 anos, entretanto, a pobreza passou a ser entendida além da dimensão estritamente econômica, sendo considerada como fenômeno multidimensional (econômico, social, político e cultural). Elaborações teóricas mais qualificadas sobre exclusão social e desfiliação estimularam o surgimento de um conjunto de medidas e indicadores ligados a mudanças no modo de produção e de acumulação capitalistas. Tais conceitos agregam noções mais dinâmicas, compreendendo processos de instabilidade ou precariedade do trabalho, fragilidade ou ruptura de vínculos sociais, empobrecimento das relações, fragmentação da sociedade, heterogeneidade dos valores centrais, limites de pertencimento em zonas de estabilidade social e novas formas de exclusão provocadas pelas reconversões industriais e tecnológicas (ESTIVILL, 2003).

A pobreza deixa de ser caracterizada pelos aspectos econômicos e passa a ser definida pelas múltiplas dimensões da vida social. O crescimento industrial, por muito tempo visto como saída milagrosa para a superação da pobreza, deixa de ser considerado um fim em si mesmo e passa a constituir-se em um meio para as pessoas ampliarem suas liberdades e sua qualidade de vida (SEN, 2001).

Nessa nova perspectiva, não se trata de superar a pobreza existente no capitalismo e, sim, criar condições e perspectivas que visem superar o próprio sistema dominante. Ao buscar uma sociedade mais justa e solidária, os fundamentos do capitalismo são questionados. Ao mesmo tempo, isso não significa que, emergencialmente, ações que se caracterizam como assistenciais e compensatórias não sejam necessárias ou que não possam promover resultados emancipatórios.

Cabe destacar o significativo esforço feito pelo governo brasileiro na última década no sentido de redução da pobreza e da desigualdade social. A política da assistência social é representativa desse esforço. No que pode ser considerado um curto período de implementação, dada sua complexidade e abrangência, ela apresenta resultados que impressionam e inspiram governantes, gestores e pesquisadores de muitos países do mundo. Porém, nenhuma política setorial sozinha consegue atingir resultados abrangentes e sustentáveis numa realidade historicamente desigual como a brasileira e com políticas marcadas pela fragmentação setorial, por programas tecnocráticos de cima para baixo - muitas vezes inadequados para a comunidade ou o público-alvo - e pela falta de articulação local com entidades da sociedade civil.

Inegavelmente, a política pública pode ser um poderoso instrumento para a construção de um desenvolvimento sustentável e inclusivo. Daí a importância de se fortalecer o debate acerca das políticas emancipatórias, aquelas em que, após a alocação de recursos materiais, humanos e técnicos, a população envolvida consiga ampliar sua autonomia e prover as condições para autossustentação econômica e autogestão.

\section{Possibilidades contra-hegemônicas}

De acordo com Ivo (2001), perspectivas metodológicas de políticas emancipatórias supõem uma nova matriz de ordenamento e governança, mais flexível, que procura apreender as novas formas de organização e interseção do tecido social nas suas relações diversificadas com a gestão da democracia, o fortalecimento da cidadania e o enfrentamento da pobreza. No âmbito institucional, essas mudanças têm envolvido: políticas de descentralização, experiências de cogestão, instauração de conselhos setoriais e comunitários, parcerias entre agentes públicos e privados, implantação de mecanismos de participação nas instâncias decisórias do planejamento e gestão dos recursos, a exemplo do orçamento participativo. A eficácia de tais princípios normativos e de estratégias institucionais está condicionada à forma como as relações políticas e econômicas locais se organizam e encaminham o processo de desenvolvimento.

É da perspectiva da construção de alternativas e formulação de nova hegemonia que se tem desen- 
volvido teses de desenvolvimento autossustentável, a qual supõe a construção de um poder local assentado numa nova cultura política, centrada na solidariedade como instrumento de libertação e articulação de energias sociais e políticas fragmentadas a partir do acesso à informação (IVO, 2001, p. 44).

Os critérios e diretrizes das políticas emancipatórias podem ser assim sintetizados:

a) Participação da população em todas as etapas e não apenas na execução. $\mathrm{O}$ diagnóstico e o planejamento participativo propiciam à população um saber sobre si mesma que a instrumentaliza para a análise crítica da situação, para a auto-organização e para a busca permanente de soluções;

b) territorialidade, que supõe a articulação entre políticas, programas e projetos dentro da mesma região, com vistas a otimizar os recursos, qualificar as ações e fomentar o desenvolvimento de potenciais humanos, econômicos, sociais e culturais endógenos;

c) intersetorialidade, que possibilita a atuação a partir do reconhecimento do caráter multidimensional, tanto da pobreza, quanto das alternativas de superação. Não basta ter o pão na mesa se a família vive o drama da dependência química ou da violência; não adianta tratar a doença, se não houver segurança; não basta ter trabalho se não houver creche para os filhos, posto de saúde, nem saneamento básico. São problemas multidimensionais e exigem ações integradas;

d) sustentabilidade, que considera a necessidade de aquisição de condições de autonomia da população ao término do Programa, permitindo-lhe prescindir dos recursos materiais e técnicos.

A busca por referenciais teórico-metodológicos compatíveis com alternativas contra-hegemônicas e efetivas no campo da superação da pobreza remete à metodologia do desenvolvimento local integrado e sustentável. Tal metodologia mostra-se capaz de atribuir caráter emancipatório às políticas públicas executadas em contextos de pobreza, pois possibilita a participação ativa da população como cogestora, ativação de recursos locais e articulação de ações setoriais no território.

Como as transformações sociais emancipatórias não ocorrem de forma espontânea e natural, é necessário explicitar o projeto subjacente, aprofundando o desejo utópico antecipador. Ou seja, partir da reflexão teórica e epistemológica acerca dos limites do sistema dominante e das possibilidades de superação com vistas à construção de uma sociedade mais justa. Isso exige que se recorra a procedimento usual de análise a partir de diferentes escalas: global, naci- onal, regional e local. Em escala local ou regional, não se deixa de admitir que mudanças podem ocorrer, ainda que globalmente a estrutura se mantenha.

Há que se considerar também que as escalas não são estanques; admitir e instaurar mudanças localizadas, embora reconhecendo que são "grãos de areia num imenso deserto", já é em si mesma uma experiência contra-hegemônica. É importante lembrar que a ampliação da globalização traz consigo, dialeticamente, o fortalecimento da localização, que, para Santos (2001), é um conjunto de iniciativas que visam criar ou manter espaços de sociabilidade de pequena escala, comunitários, assentes em relações face a face, orientados para autossustentabilidade e regidos por lógicas cooperativas e participativas. Embora periféricas e subalternas, as experiências emancipatórias estão profundamente relacionadas à escala local e podem ser contra-hegemônicas.

Isso não implica, necessariamente, no fechamento isolacionista que leva ao comunitarismo regressivo, mas medidas de proteção contra investidas predadoras do sistema dominante. Cabe ainda destacar que o desenvolvimento local é uma das inúmeras alternativas ou procedimentos necessários para a superação sustentável da pobreza, a ser combinado com políticas estruturantes, políticas setoriais e compensatórias, taxações de grandes riquezas e outros mecanismos de redistribuição, geração de emprego e renda, transferência ou posse de ativos e oportunidades igualitárias.

\section{Uma experiência bem sucedida}

Estão em curso, atualmente, incontáveis experiências contra-hegemônicas materializadas pela Economia Solidária, pelos Orçamentos Participativos e por políticas públicas alternativas (CATTANI et al.; GAIGER, 2004). O exemplo escolhido para dar destaque a uma experiência bem sucedida foi o Pirad, coordenado pela Metroplan-RS e executado em parceria com a Sociedade de Cooperação Alemã (GTZ) e a Refinaria Alberto Pasqualini-Petrobrás (Refap), no período de 1999 a 2002, em três grandes regiões ligadas a sub-bacias de arroios em áreas ambientalmente degradadas e onze municípios no estado do Rio Grande do Sul.

Esse programa foi peculiar por várias razões. Primeiramente, pelo fato de a Metroplan não ser uma fundação ligada à área da assistência social, trabalho ou desenvolvimento. Em segundo lugar, por não ser objetivo precípuo do Pirad o combate à pobreza, mas a recuperação urbana e ambiental de áreas degradadas. Por último, pelo fato de ter permitido a promoção de processos considerados sustentáveis na superação da pobreza através de sua concepção integrada, participativa e territorializada. Os resultados 
positivos ensejaram uma pesquisa aprofundada buscando conhecer uma metodologia que pudesse transcender certa área específica das políticas públicas e ser utilizada ou replicada de forma intersetorial, oportunizando o envolvimento das diversas áreas e seus agentes na complexa e prioritária questão da superação emancipatória da pobreza na realidade contemporânea.

\section{Metodologia da pesquisa}

A pesquisa foi desenvolvida ao longo de quatro anos, de 2003 a 2006.

Inicialmente, a coleta de dados foi realizada através de pesquisa documental na Metroplan, organização regional responsável pela execução do Pirad. Os técnicos disponibilizaram relatórios a partir dos quais foi possível fazer um levantamento acerca da história, concepções norteadoras, implementação e avaliação do Programa. Posteriormente, foram realizadas entrevistas semiestruturadas com oito gestores das três organizações envolvidas. Três gestores eram funcionários públicos ligados à Metroplan e cinco foram contratados como agentes locais da GTZ devido à sua qualificação técnica e experiências anteriores em processos participativos. Por último, foi realizado um estudo de caso no bairro Guajuviras, situado no município de Canoas, região metropolitana de Porto Alegre.

$\mathrm{O}$ estudo de caso foi realizado ao longo de três anos (2004 a 2006) através de observação participante e da realização de entrevistas semiestruturadas com cinco moradores do bairro que participaram ativamente das etapas do Pirad. As entrevistas foram realizadas no período de junho a julho de 2006 em Porto Alegre e municípios próximos.

Tratou-se esta de pesquisa de doutorado de Ferrarini, realizada no período de 2005 a 2007 (FERRARINI, 2008), que contou com acompanhamento permanente do professor orientador, de professores de metodologia de pesquisa e obteve a aprovação da banca. Todos os procedimentos respeitaram a Resolução n. 196 do Conselho Nacional de Saúde, item IV, que trata do consentimento livre e esclarecido, que foi formalmente solicitado e obtido dos participantes. Ainda em observação à mencionada Resolução, foi mantido o anonimato dos sujeitos da pesquisa com identificação por situação e numérica.

\section{Resultados}

Os princípios e estratégias metodológicas foram igualmente aplicados em cada um das sub-bacias em que o Pirad foi desenvolvido. Foram capacitadas 570 lideranças através de centenas de cursos, oficinas e atividades ligadas aos processos da gestão participativa do Programa. Indiretamente, cerca de 400 mil habitantes foram beneficiados através de obras de infraestrutura, muitas com recursos do orçamento participativo estadual, e de programas educativos, de geração de renda realizados em parceria com programas da área do trabalho, cooperativismo e economia solidária. Ao todo, foram formados 15 núcleos comunitários e um Fórum Regional de Desenvolvimento composto por ampla diversidade de atores, representantes de organizações comunitárias, dos poderes públicos municipal, estadual e federal, setor privado, instituições de ensino e organizações não governamentais. A aceitação desse processo pela população local foi positiva e resultou na alocação de mais de três milhões de reais através do orçamento participativo de 2002 para a implementação de melhorias urbanas e de apoio para atividade de geração de trabalho e renda (BARTH; BROSE, 2002, p. 70).

A primeira característica fundamental do Pirad foi a utilização de metodologias participativas que, geralmente, produzem alterações nas organizações. A participação não é algo que acontece da instituição para fora, ela também passa a ser vivenciada pelos próprios agentes, gerando, muitas vezes, dilemas técnicos e organizacionais. Nesse caso, houve três campos de divergências, os quais serão identificados e analisados ao longo do relato: entre a Metroplan e a GTZ, entre técnicos da Metroplan e entre os agentes e a população envolvida.

Entre a Metroplan e a GTZ, inicialmente houve um choque entre a cultura alemã mais rígida, baseada em planejamentos minuciosos e metodologias que, apesar de enriquecedoras, nem sempre poderiam ser aplicadas diretamente à realidade. $\mathrm{O}$ elemento marcante para a superação desses impasses foi a sensibilidade e a habilidade das coordenações técnicas em flexibilizar e até alterar certas tradições, recriando metodologias na relação direta com o contexto social. As metodologias participativas visavam fomentar o protagonismo da população desde o planejamento das ações e não apenas na execução.

\begin{abstract}
Nós não fazemos nada por ninguém. Fazer e dar pronto não é valorizado. Se a prefeitura vem com um caminhão para limpar a área, chamamos todos para fazer um mutirão e ajudar; assim, depois todos vão ajudar a manter limpo (gestor 1).
\end{abstract}

Apesar de haver recursos e intenção dos agentes em desenvolver o trabalho, as comunidades aderiam de forma voluntária.

Fiquei especialista em apresentar o projeto. Se a comunidade se interessava, se começava a fazer a formação. Primeiro, começamos a montar a forma- 
ção com eles. Quando eu chegava à comunidade, identificava as lideranças, não as políticas, mas o padre, ex-presidiários, as 'lideranças negativas' também. Mapeava para chegar com o carro e não ter tiroteio (gestor 8).

As lideranças formavam o Núcleo Comunitário de Desenvolvimento que, inicialmente, se reunia de maneira informal para depois assumir identidade jurídica própria e desempenhar crescente autonomia de ação no Programa; era uma forma de oportunizar e fortalecer o processo de cogestão da política.

No Núcleo tinha, desde a Igreja até o clube de futebol, e muitos estão mobilizados até hoje (gestor 8).

Os moradores participavam do desenvolvimento do Programa constituído de três etapas. A primeira visava à formação de lideranças. Começar o trabalho através das lideranças, permitia o aproveitamento da riqueza social existente na comunidade; tratava-se de considerar a história e fortalecer o que já existia.

As pessoas que tinham atividades dentro do Núcleo convidavam outros moradores com potencial para o trabalho comunitário, com vistas a aflorar a liderança que cada um tem dentro de si (gestor 6).

A intenção era a ampliação da participação de grupos excluídos, evitando a concentração de poder nas lideranças que, apesar de bem intencionadas, acumulavam tarefas, saberes e recursos, configurando um tipo de elite dentro da comunidade, em parte alimentada por certa apatia e desesperança de muitos moradores. Os cursos de capacitação tratavam sobre a função e o comportamento de lideranças (refletir seu papel na comunidade); capacitação das lideranças para o aprofundamento do trabalho participativo em grupo e desenvolvimento de alguma atividade econômica na perspectiva do desenvolvimento local.

Os cursos foram montados e aperfeiçoados pelos técnicos e formadores ao longo dos anos, desde 1994 até 1998 (período em que a GTZ desenvolveu um programa precursor, o Prorenda). Em primeiro lugar, houve um aperfeiçoamento com relação ao conteúdo:

Tínhamos críticas pela formação muito simplista, técnica, que ficava muito na formação do indivíduo sem focar no coletivo. Tinha feudos na comunidade, pela formação de um indivíduo que se sobressaía e não havia mecanismos para eles se reunirem. O indivíduo falava por ele, e não pelo grupo. Outra coisa é uma forma muito simplista de gerar renda, acaba sendo a sobrevivência com dificuldades. A maioria da população vive em situação de pobreza, é preciso superar a exclusão total dos que estão abaixo da linha da pobreza, para se ter dignidade. Não se trata nem de superar, mas de garantir acesso básico, a melhoria da autoestima (gestor 7).

A didática também foi aperfeiçoada:

Não adiantava chegar na comunidade que trabalhava o dia todo com conteúdos teóricos, densos. Por isso, organizou-se um conjunto de dinâmicas grupais de quatro horas e depois se fazia uma reflexão sobre o papel da liderança e do grupo. Também se destacava a importância das pessoas planejarem sua ação [...]. Para a comunicação, se trabalhava com técnicas de moderação e de visualização. Há estudos que mostram que as pessoas só absorvem $10 \%$ do que ouvem. De forma visual, absorvem de $30 \%$ a $35 \%$. Falando, discutindo, vivenciando e visualizando chegam até $40 \%$ (gestor 6).

$\mathrm{O}$ acompanhamento às lideranças no processo de capacitação e formação dos Núcleos se dava através de reuniões semanais. Nessa etapa, era feito o diagnóstico das comunidades através do Diagnóstico Rápido Urbano Econômico Participativo (Druep). Os técnicos repassavam conhecimentos à população para que ela fizesse seu próprio diagnóstico através de metodologias de diagnósticos rápidos urbanos participativos $^{1}$. Essa metodologia desencadeou um impasse interno na Metroplan. A resistência ocorreu por parte dos técnicos que já estavam acostumados com a contratação de profissionais para a elaboração de diagnósticos, o que é muito mais fácil, rápido e, geralmente, menos oneroso.

O grupo de arquitetos achava que tinha que ter um entendimento de tudo, tinha que se fazer um grande levantamento, um diagnóstico muito extenso. Anos depois vimos que não era necessário, que uma amostra já era suficiente, isso ainda no Prorenda (gestor 9).

Outro elemento importante é a impossibilidade de anular o saber que a população adquire a partir do momento em que ela se reúne para identificar, analisar e compreender suas próprias demandas. Uma das técnicas do Druep era o "mapa falante", um conjunto de fotografias de áreas degradadas do bairro e de situações consideradas problemáticas que necessitavam de intervenção. Outra técnica consistia de entrevistas com perguntas abertas e fechadas com uma amostra de moradores do bairro através de visitas domiciliares.

As pessoas lembram, eles chegavam através do Druep, iam para a comunidade com os questionários. Nem sempre eles aceitavam que a prioridade era a da comunidade (gestor 8). 
Após o trabalho de campo, as lideranças elaboravam o diagnóstico preliminar em parceria com os técnicos e davam, de imediato, o primeiro retorno para os moradores entrevistados. Essa era uma estratégia que tinha por objetivo evitar a utilização da comunidade como objeto de conhecimento, sem que ela se percebesse como sujeito desse saber.

A segunda etapa de trabalho dos moradores consistia na definição das prioridades e sistematização do Plano de Desenvolvimento Local Integrado (PDLI) que apontava as melhorias físicas e sociais necessárias. O Plano era encaminhado às respectivas secretarias e órgãos de execução, já articulados com o Pirad, os quais viam a possibilidade de priorizar as necessidades do PDLI dentro dos recursos disponíveis; tais órgãos definiam o que podia ser feito e davam resposta rápida à comunidade.

A terceira etapa era a organização comunitária em busca de recursos no orçamento participativo com vistas à ampliação das melhorias feitas, ao atendimento de demandas que não puderam ser executadas ou à viabilização de propostas inovadoras; a disputa pela prioridade de projetos era a maior dificuldade.

A articulação com as organizações públicas, privadas e sociedade civil ocorria de acordo com a realidade de cada região e município. A instância privilegiada de articulação eram os fóruns regionais. A articulação era complexa, pois havia intercruzamento entre esferas distintas (comunitária, municipal e regional) e entre diferentes setores da sociedade.

O bairro Guajuviras foi uma das comunidades onde o Pirad foi executado por localizar-se próximo a um arroio, em área ambientalmente degradada. $\mathrm{O}$ bairro situa-se no município de Canoas, o mais importante centro econômico do estado depois da capital, mas caracterizado por imensa desigualdade social, que se expressa pela significativa extensão de comunidades pobres em sua periferia. $\mathrm{O}$ bairro Guajuviras tinha população aproximada de 70 mil habitantes. Grande parcela da população vivia em situação de pobreza ou indigência, sem acesso a saneamento básico, com políticas públicas insuficientes frente à demanda $\mathrm{e}$ alto índice de desemprego; é também conhecido como o bairro mais violento do estado.

Segundo relatos de lideranças, a associação de moradores teve um papel fundamental no trabalho da Metroplan. No início, as lideranças se encarregavam de buscar pessoas interessadas em participar da capacitação, vivenciando limites e conquistas.

Eu não sei se é o capitalismo que tá na cabeça das pessoas. A gente vai convidar, a primeira coisa que perguntam é: Ganha alguma coisa? Tem que não pensar neste lado, tem que se doar. Mesmo que tenha dificuldade e necessidade, um dia chega (morador 1).
O Druep foi executado por um grupo de 18 pessoas e foi feito o diagnóstico de todo o bairro (das áreas degradadas e das áreas ocupadas).

Naquele trabalho de pesquisa, a gente descobriu muita coisa interessante. Se tirou foto, se fez todo um relatório disso, dos problemas, dos buracos, do lixo, da questão do transporte, tudo. Então, ela foi muito ampla e muito interessante e não se gastou dinheiro porque nós mesmos, cada um, pegou 20 pesquisas e fazia no seu setor. Aquilo para mim foi uma coisa muito inovadora. E outra, a gente chegou a algumas conclusões, a gente viu que girava muito em torno da geração de renda, que as pessoas às vezes não tinham renda nenhuma (morador 3 ).

Com relação às prioridades do bairro Guajuviras,

O que mais empolgou a comunidade foi a ação de trabalho e renda e depois o meio ambiente. A educação ambiental teve sucesso porque pegou as escolas. Tem uma série de obras feitas, mas a maior é a conscientização da comunidade (gestor 8).

Isso gerou várias iniciativas de desenvolvimento econômico local, como o galpão de reciclagem, conseguido através de recursos do Orçamento Participativo conquistados pela comunidade. Outra importante iniciativa foi a implantação do primeiro clube de trocas solidárias com moeda local.

Se você chama os moradores para vir discutir sobre um determinado tema, eles não vão porque hoje a preocupação deles é outra [...]. Com a questão do troca-troca, que foi uma das coisas que a gente achou que era possível, tu reunia um monte de gente, era uma coisa aberta, tu proporcionava várias coisas numa comunidade para as pessoas participarem produzissem e que fossem. Ali era um espaço onde tu passaria ' $n$ ' informações, nós fizemos oficinas etc. (morador 2).

Houve também a criação de grupos de trabalho, de cooperativas e associações.

A gente vê que os grupos de geração de trabalho e renda foram discutindo, dentro dessa metodologia que foi aplicada, que eles podiam ser autogestionários, que podiam ser autônomos, ter uma casa para que pudessem comercializar o produto, fabricar seu produto (morador 3 ).

Atualmente, oito anos após o término do Pirad, as lideranças continuam se fortalecendo e buscando recursos para a comunidade.

Mudamos a estratégia e fizemos um projeto de todos os grupos do Guajuviras e fomos bater de por- 
ta em porta das entidades. E foi isso que deu certo. Tinha mais grupos também. Nós reunimos: artesanato, as promotoras legais populares, os dois clubes de troca, Arlas $^{2}$ e essa questão do meio ambiente também era uma questão de educação. Fizemos mutirão para plantar árvore, tirar lixo, tava muito sujo (morador 2).

De acordo com a fala de um dos gestores:

Na maioria das comunidades deu certo, mas não se manteve. Parou quando estava no bom ponto de trabalho (entrevistado 8).

A interrupção brusca devido à troca de governo é referida, tanto pelos gestores quanto pelo público-alvo, como o principal fator de prejuízo aos resultados do Pirad.

Não tem solução para o RS ou para cidades em quatro anos. Para buscar soluções para as comunidades, primeiro, tem que ter o tema da integralidade e, segundo, tem que planejar mesmo para 20 anos, senão não tem saída (gestor 3).

O Pirad foi extinto precocemente, considerando que deveria ser um projeto com vigência de médio a longo prazo para consolidação plena de seus objetivos.

\section{Conclusão}

Assistir ou emancipar? Estudos recentes e o conhecimento acerca da realidade das comunidades empobrecidas mostram que a pobreza é um fenômeno estrutural e multidimensional e que as demandas da população pauperizada são complexas e heterogêneas, exigindo um conjunto diversificado de ações e programas. Políticas compensatórias são imprescindíveis para amenizar as múltiplas expressões da questão social e fortalecer os sujeitos envolvidos, mas precisam ser conectadas com procedimentos capazes de oportunizar a autossustentação das famílias e comunidades atendidas, atribuindo sustentabilidade às ações. Assistir e emancipar deixam de constituir-se em processos concorrentes ou contraditórios e passam a ser indissociáveis; trata-se de assistir emancipando e emancipar assistindo.
Contudo, na prática, apesar dos avanços nas proposições e formulações de políticas e programas, observam-se significativos limites para a integração de ações e a efetividade dos resultados. Daí a proposta de desenvolvimento local integrado e sustentável que focaliza o território através, principalmente, da ampliação e qualificação da participação dos sujeitos e da ativação dos recursos endógenos da comunidade. $\mathrm{O}$ conhecimento sobre as vantagens e limites da metodologia do desenvolvimento local ligada à gestão de políticas públicas tem a intenção de compartilhar saberes e práticas que possam ser replicados pelas políticas públicas em geral.

$\mathrm{O}$ aspecto mais relevante, simultaneamente expresso como vantagem e como desafio, é o uso de metodologias participativas. A população torna-se cogestora e não mera executora das ações de programas. Ninguém lhe tira o saber adquirido sobre si mesma. Além disso, a aprendizagem de "andar com as próprias pernas" na busca de recursos lhe oportuniza a conquista de resultados não restritos ao tempo do programa, atribuindo sustentabilidade às ações.

Nesse caso, a sustentabilidade pode ser compreendida de forma correspondente às múltiplas dimensões da pobreza, caracterizando processos de superação ou reversão de cada uma delas. A sustentabilidade econômica se expressou pelo controle e gestão dos recursos produtivos e dos resultados do próprio trabalho da população envolvida, através do acesso a crédito, ao mercado, ao trabalho e da constituição de empresas ou cooperativas. A sustentabilidade social foi obtida através da união das pessoas e da comunidade sob a forma de redes e teias cooperativadas de trocas de bens, serviços, ideias, favores, gestos de desprendimento e de partilha. A sustentabilidade política foi exercitada pela organização coletiva em busca da garantia de direitos e de oportunidades.

A questão do tempo está metodologias participativas. A população torna-se cogestora e não mera executora das ações de programas. Ninguém lhe tira o saber adquirido sobre si mesma. ligada ao processo. O exercício da participação, mudança de uma cultura política de passividade e de dependência, aprendizagem sobre os procedimentos de captação de recursos são resultados de médio e longo prazo. Clareza e discussão com a população envolvida sobre o "tempo social" de cada etapa são requisitos indispensáveis. A esse respeito, foi possível observar também que, por um lado, a participação sem pequenas conquistas materiais desmobiliza, por outro, a alocação de recursos mate- 
riais ou econômicos sem a mobilização da população pode ser improdutiva.

Daí a impactante constatação de que processos emancipatórios no Pirad não foram desencadeados exclusiva ou prioritariamente por recursos materiais e financeiros, mas por recursos imateriais, simbólicos, pelo resgate de saberes da população e pela crença na sua capacidade. Os recursos financeiros vinham depois da mobilização e organização da população, o que pode ser atribuído ao fato de as estruturas criadas terem sido perenizadas e a continuidade ao acesso de recursos após o término do Programa, sem assessoria de técnicos.

Outro elemento fundamental foi o desenvolvimento de iniciativas de geração de trabalho e renda, nesse caso, ligados à economia solidária. Tais iniciativas não se restringem aos tradicionais cursos profissionalizantes e busca por emprego e postos de trabalho, mas visam a formação de grupos de trabalho, cooperativas, redes de comercialização e clubes de trocas com moeda social. A necessidade de subsistência obviamente mobiliza os envolvidos e os impactos de atividades produtivas mostraram-se fundamentais para a elevação da autoestima, motivação e adesão às atividades.

O caráter participativo torna impossível a exata repetição de experiências. Os objetivos definidos, as atividades executadas e os resultados são singulares, variando de acordo com a decisão dos sujeitos e as características socioculturais, econômicas e políticas de cada contexto. É como se, em parte, o rumo do processo escapasse das mãos dos técnicos, porém os princípios e estratégias metodológicas podem ser replicados.

$\mathrm{Na}$ perspectiva do desenvolvimento local integrado e sustentável, a análise do Pirad permite sinalizar alguns limites e desafios às políticas públicas. Em primeiro lugar, a descontinuidade foi identificada como a maior limitação do Programa, pois foi reproduzida a tradicional prática de extinção das ações por ocasião da mudança de governo. Essa foi a maior frustração expressa pelos técnicos, e, principalmente, pela população, que acreditou, que se mobilizou e viu o processo acabar quando estava em ritmo acelerado de execução. No Brasil, parece inevitável que as pesquisas demonstrem repetidamente os malefícios de se tratar política pública como política de governo.

Em segundo lugar, ficou evidente a necessidade de instaurar arranjos organizacionais inter- secretarias para a constituição de organizações mediadoras nas comunidades e contratação de agentes de desenvolvimento local. Tais agentes podem criar condições para a transformação de aportes materiais, humanos e financeiros das políticas setoriais em "pretextos político-pedagógicos" para o exercício da participação e da cidadania. A pes- quisa sugere que a otimização e a perenização dos aportes compensam investimentos públicos em médio prazo.

Em terceiro lugar, destaca-se a necessidade de fortalecer atividades de formação integral de gestores e agentes das políticas públicas, pois se atribui expressiva parcela de êxito do Pirad às habilidades comunicacionais, sensibilidade e atitudes de solidariedade e respeito aos saberes e valores da população local. Além disso, a clareza e a identificação pessoal dos gestores e dos agentes com relação ao projeto ético-político emancipatório mostrouse relevante. Porém, o que mais chamou a atenção foi o "brilho nos olhos" dos técnicos que, durante as entrevistas, lembravam saudosos dos momentos e dos processos vivenciados nas comunidades. Por melhor que seja o planejamento, o programa se materializa e ganha vida através da voz e da ação cotidiana dos técnicos. E ambos - técnicos e população local - constituem-se como cidadãos em cada conquista na longa jornada de construção de uma sociedade mais justa e sustentável.

\section{Referências}

BARTH, J.; BROSE, M. Participação e desenvolvimento local: balanço de uma década de cooperação alemã no Rio Grande do Sul. Porto Alegre: Sulina, 2002.

CATTANI,A.D.; GAIGER, L I.; LAVILLE, J.-L.; ESPANHA, P. (Org.). Dicionário internacional da outra economia. Coimbra: Almedina, 2009.

COMIM, F.; BAGOLIN, I. Aspectos qualitativos da pobreza no Rio Grande do Sul. Ensaios FEE, Porto Alegre, v. 23, n. especial, p. 467-490, 2002.

ESTIVILL, J. Panorama da luta contra a exclusão social. Conceitos e estratégias. Genebra: Bureau Internacional do Trabalho, Programa Estratégias e Técnicas contra a Exclusão Social e a Pobreza, 2003.

FERRARINI, A.V. Pobreza: possibilidades de construção de políticas emancipatórias. São Leopoldo: Oikos, 2008.

GAIGER, L. I. (Org.). Sentidos e experiências da economia solidária no Brasil. Porto Alegre: Editora da Ufrgs, 2004.

IVO, A. B. L. Metamorfoses da questão democrática: governabilidade e pobreza. Buenos Aires: Clacso, 2001.

SANTOS, B. de S. Globalização: fatalidade ou utopia. Lisboa: Afrontamento, 2001.

SEN, A. Desenvolvimento como liberdade. São Paulo: Companhia das Letras, 2000. 


\section{Notas}

1 Foram sendo experimentadas e melhoradas ao longo dos anos, tendo sido utilizadas como Diagnóstico Rápido Participativo(DRP), Diagnóstico RápidoUrbano Participativo (DRUP) e, finalmente, Diagnóstico Rápido Urbano Econômico Participativo(Druep).

2 Associação de Recicladoras Amigas Solidárias, uma organização popular que se formou no bairro nesse período.

\section{Antonio David Cattani}

www.antoniodavidcattani.net

Pós-Doutorado, École de Hautes Études en Sciences Sociales, Paris

Doutorado em Economia do Desenvolvimento pela Université Paris

Professor titular de Sociologia da Universidade Federal do Rio Grande do Sul (Ufrgs) e do Programa de Pós-Graduação em Sociologia (PPGS)

Pesquisador visitante na Universidade de Oxford (2010-2011)

\section{Ufrgs - PPGS}

Av. Bento Gonçalves, 9.500 - Sala 103

IFCH Campus do Vale

Porto Alegre - Rio Grande do Sul

CEP: $91509-900$

\section{Adriane Vieira Ferrarini}

adrianevf@unisinos.br

Doutorado em Sociologia pela Universidade Federal do Rio Grande do Sul (UFRGS), com período sanduíche na Universidade de Coimbra. Orientador: Boaventura de Sousa Santos

Professora do Programa de Pós-Graduação em Ciências Sociais da Universidade do Vale do Rio dos Sinos (Unisinos)

\section{Unisinos - PPGCS}

Av. Unisinos, 950

Cristo Redentor

São Leopoldo - Rio Grande do Sul

CEP: 93022-000 